\title{
Anaerobic Growth of Escherichia coli K12 with Fumarate as Terminal Electron Acceptor. Genetic Studies with Menaquinone and Fluoroacetate-resistant Mutants
}

\author{
By JOHN R. GUEST \\ Department of Microbiology, University of Sheffield, Sheffield S10 2TN
}

(Received 22 March 1979)

Fifteen independent menaquinone biosynthesis mutants (men) of Escherichia coli K12, selected for their inability to use fumarate as terminal electron acceptor, were investigated. Two nutritionally distinct groups were detected. The major group (13 mutants) responded to 1,4-dihydroxy-2-naphthoate (DHN), 2-succinylbenzoate (SB) and its dilactone, whereas the minor group (2 mutants) only responded to DHN. DHN was at least five times more effective than SB but it inhibited growth at concentrations greater than $10 \mu \mathrm{M}$. For anaerobic growth on glucose minimal medium the auxotrophs responded to much lower concentrations of DHN and SB and these intermediates could be replaced by uracil. Anaerobic growth tests showed that glycerol, formate and $\mathrm{H}_{2}$ are good substrates for $E$. coli when fumarate is the ultimate electron acceptor but growth with lactate or with fumarate alone is poor.

All 15 men mutations were located between $g l p T$ and $p u r F$ at approximately $49 \mathrm{~min}$ in the $E$. coli linkage map. Cotransduction frequencies with relevant markers were: nalA $(21 \%)$, $\operatorname{glp} T(35 \%)$ and $\operatorname{pur} F(15 \%)$. The presence of at least three genetically distinct classes (men $C$ and $m e n D$, SB-requirers; $\operatorname{men} B, \mathrm{DHN}$-requirers) was indicated using abortive transduction as a complementation test and three-factor genetic analysis. The relative orientation nalA...men $C-(D, B) \ldots$ pur $F$ was indicated.

Fluoroacetate-resistant mutants were isolated and four different classes were identified: $a c k$, lacking acetate kinase; pta, lacking phosphotransacetylase; fac $A$, lacking both of these activities; and $f a c B$, which retained both of these enzyme activities. Some of the pta mutants and all of the fac $A$ mutants failed to grow on media containing fumarate as terminal electron acceptor or anaerobically on glucose minimal medium. All four types had genetic lesions clustered between the men and purF sites. Average cotransduction frequencies with relevant markers were: nalA (4\%), men (27 to $35 \%$ ) and purF (71 to $80 \%$ ).

\section{INTRODUCTION}

Fumarate functions as an anaerobic electron acceptor in the metabolism of many obligate and facultative anaerobes. It not only provides a sink for reducing equivalents but, more important, the reduction of fumarate can be coupled to a unique proton-translocating and ADP-phosphorylating electron transport chain (Kröger, 1977, 1978; Haddock \& Jones, 1977; Gottschalk \& Andreesen, 1979). Hence, the presence of fumarate enables Escherichia coli to grow anaerobically with glycerol, $\alpha$-glycerophosphate, lactate, formate or molecular hydrogen as carbon and/or energy sources. Menaquinones are essential redox carriers for transporting electrons to fumarate. Consequently, mutants of $E$. coli blocked in menaquinone biosynthesis fail to grow on non-fermentable substrates with fumarate as terminal electron acceptor, but can grow in the presence of oxygen or nitrate (Lambden \& Guest, 1976; Guest, 1977). Fumarate also has important anabolic functions. It serves as the 
preferred oxidant in the menaquinone-dependent conversions of dihydro-orotate to orotate and protoporphyrinogen to protoporphyrin during anaerobic pyrimidine and porphyrin synthesis in E. coli (Newton et al., 1971; Jacobs \& Jacobs, 1978) and it is a source of succinate (succinyl-CoA) for biosynthetic purposes during anaerobic growth (Creaghan \& Guest, 1978).

The pathway proposed for the synthesis of bacterial menaquinone (MK) from chorismate proceeds via 2-succinylbenzoate (SB), 1,4-dihydroxy-2-naphthoate (DHN) and demethylmenaquinone (DMK) and involves at least three genes (Young, 1975; Guest, 1977):

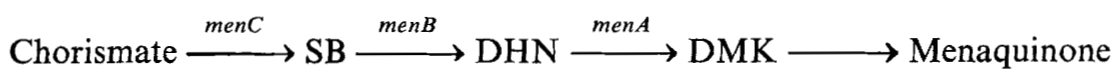

Details of the early steps have not been established and it is possible that other intermediates, derived from or giving rise to the proposed intermediates, may be involved.

Mutants of $E$. coli K12 lacking menaquinone were first isolated during a search for ubiquinone mutants and two distinct genetic classes were defined (Young, 1975). One class, represented by five mutants, had lesions in the men $A$ gene located at $86.7 \mathrm{~min}$ in the $E$. coli linkage map. This class is characterized by the accumulation of DHN and the lack of the corresponding octaprenyltransferase needed to convert this intermediate to DMK (Shineberg \& Young, 1976). Members of the second class (two mutants) had lesions in a gene (menB) which is not cotransducible with the menA gene and they accumulated SB, as if blocked in the cyclization of this intermediate (see scheme above). More recently, menaquinone mutants were found amongst mutants selected for their inability to use fumarate as a terminal electron acceptor for anaerobic growth (Lambden \& Guest, 1976). Studies with two mutants showed that normal anaerobic growth and menaquinone synthesis could be restored with exogenous SB, consistent with a lesion in the biosynthesis of this intermediate (Guest, 1977). The corresponding mutations were located at approximately $49 \mathrm{~min}$ in the recalibrated linkage map of $E$. coli (Bachmann et al., 1976) in a gene designated menC.

As part of an investigation of the early steps in menaquinone biosynthesis, further men mutants, selected for their inability to use fumarate as terminal electron acceptor unless supplied with precursors, SB or DHN, have been isolated. In this paper, the nutritional and genetic characteristics of 15 such mutants are reported, together with evidence indicating the presence of a cluster of at least three men genes in the menC region of the linkage map. Genetic studies with fluoroacetate-resistant mutants and the effects of the corresponding mutations on the ability to use fumarate as electron acceptor are also reported.

\section{METHODS}

Organisms. The strains used were all derivatives of Escherichia coli K12 (Table 1). Originally, the menaquinone mutants were isolated from strain PL2024 as a class of mutant unable to grow anaerobically on LF medium (men-1 to -3; Lambden \& Guest, 1976). In this work they were isolated from strain JRG911, more specifically, as auxotrophs by using LF medium supplemented with SB (men-4 to -7) or with DHN $(m e n-8$ to -15$)$ as permissive media. Nalidixic acid resistant $\left(\mathrm{Nal}^{\mathrm{R}}\right)$ derivatives were selected as spontaneous mutants and $\mathrm{Nal}^{\mathrm{s}}$ derivatives were obtained by cotransduction of men with purF $F^{+}$using JRG896 (purF) as the $\mathrm{Nal}^{\mathrm{S}}$ recipient. Independent fluoroacetate-resistant $\left(\mathrm{Fac}^{\mathrm{R}}\right)$ mutants were isolated from several parental strains and allocated $f a c$ allele numbers (Table 1). Some were subsequently characterized as acetate kinase (ack) or phosphotransacetylase (pta) mutants but the original allele numbers were used with the new gene symbols.

Media. The media and growth conditions have been described previously (Lambden \& Guest, 1976; Guest, 1977): LF, GF and FF refer to minimal salts media with fumarate containing lactate, glycerol and formate, respectively, and $\mathbf{F}$ refers to minimal salts medium containing fumarate alone. The major substrates were present at $40 \mathrm{mM}$ and all the above media were supplemented with acid-hydrolysed casein $\left(0 \cdot 5 \mathrm{~g}^{-1}\right)$. Other minimal media contained, as major substrates, glucose (10 or $30 \mathrm{~mm})$, sodium DL- $\alpha$-glycerophosphate $(20 \mathrm{~mm})$ or pyruvate $(25 \mathrm{~mm})$. Media were supplemented with amino acids, purines, pyrimidines and vitamins according to the requirements of individual strains. Anaerobic incubation was under $\mathrm{H}_{2} / \mathrm{CO}_{2}(95: 5, \mathrm{v} / \mathrm{v})$ 


\section{Table 1. Strains of Escherichia coli K12}

\begin{tabular}{|c|c|c|}
\hline Strain & Relevant characteristics & Source or derivation \\
\hline PL2024 & $\mathrm{F}^{-} ;$gal trpA $\operatorname{trp} R$ iclR $\operatorname{rps} L$ & Lambden \& Guest (1976) \\
\hline JRG911 & $\mathrm{F}^{-} ;$gal trp $A$ trp $R$ iclR $\operatorname{rps} L$ nalA & Spontaneous $\mathrm{Nal}^{\mathrm{R}}$ mutant of PL2024 \\
\hline JRG896 & $\mathrm{F}^{-} ; \operatorname{trp} R$ iclR purF54 & Guest (1977) \\
\hline JRG979 & $\mathrm{F}^{-} ; \operatorname{trpR}$ iclR purF54 nalA & Spontaneous Nal ${ }^{\mathrm{R}}$ mutant of JRG896 \\
\hline Lin6 & $\mathrm{F}^{-} ;$glpT13 phoA relA tonA22 $\mathrm{T}_{2}^{\mathrm{R}}$ & Hayashi et al. (1964) \\
\hline AW9 & $\mathrm{F} 14 ;$ met $^{+}$sup $U /$ metB rec $A 56$ & J. Scaife \\
\hline KLF29/JC1553 & $\begin{array}{l}\text { F129; his } / \text { argG6 metBl his leu recAl } \\
\text { mtl xyl malA gal lac rpsL tonA supE44 } \\
\text { tsx }\end{array}$ & Low (1972) \\
\hline JRG862 & $\operatorname{men} C l$ & Men $^{-}$mutant of PL2024 (Guest, 1977) \\
\hline JRG863 & $\operatorname{men} C 2$ & Men- mutant of PL2024 (Guest, 1977) \\
\hline JRG860 & menC3 & $\begin{array}{l}\text { Men }{ }^{-} \text {mutant of PL2024 (Lambden \& Guest, } \\
\text { 1976) }\end{array}$ \\
\hline JRG915 & menC4 nalA & \\
\hline JRG916 & menD5 nalA & \\
\hline JRG917 & menD6 nalA & \\
\hline JRG918 & menD7 nalA & \\
\hline JRG952 & menC8 nalA & \\
\hline JRG953 & menC9 nalA & Men $^{-}$mutants of JRG911 \\
\hline JRG954 & menBIO nalA & \\
\hline JRG955 & men-11 nalA & \\
\hline JRG956 & men-12 nalA & \\
\hline JRG959 & men-13 nalA & \\
\hline JRG961 & menC14 nalA & \\
\hline JRG962 & men-15 nalA & \\
\hline JRG902 & menCl nalA & Spontaneous $\mathrm{Nal}^{\mathrm{R}}$ mutant of JRG862 \\
\hline JRG903 & $\operatorname{men} C 2$ nalA & Spontaneous $\mathrm{NaI}^{\mathrm{R}}$ mutant of JRG863 \\
\hline JRG914 & menC3 nalA & Spontaneous $\mathrm{Nal}^{\mathrm{R}}$ mutant of JRG860 \\
\hline JRG 1047 & menD7 & $\begin{array}{l}\text { Pur }^{+}\left(\mathrm{Men}^{-} \mathrm{Nal}^{\mathrm{S}} \mathrm{P1}^{\mathrm{s}}\right) \text { transductant from } \\
\text { JRG918 into JRG896 }\end{array}$ \\
\hline JRG1049 & men $B 10$ & $\begin{array}{l}\mathrm{Pur}^{+}\left(\mathrm{Men}^{-} \mathrm{Nal}^{\mathrm{S}} \mathrm{P1}^{\mathrm{s}}\right) \text { transductant from } \\
\text { JRG954 into JRG896 }\end{array}$ \\
\hline JRG1051-9 & fac- 1 to -9 menBlo nalA & Spontaneous Fac ${ }^{\mathbf{R}}$ mutants of JRG954 \\
\hline JRG1061-9 & fac -11 to -19 & Spontaneous Fac ${ }^{\mathbf{R}}$ mutants of PL2024 \\
\hline JRG1071-9 & fac -21 to -29 nalA & Spontaneous Fac $^{\mathbf{R}}$ mutants of JRG911 \\
\hline JRG1081-9 & fac -31 to -39 purF & Spontaneous $\mathrm{Fac}^{\mathrm{R}}$ mutants of JRG896 \\
\hline JRG1091-9 & fac -41 to -49 purF nal $A$ & Spontaneous Fac ${ }^{\mathbf{R}}$ mutants of JRG979 \\
\hline
\end{tabular}

unless otherwise stated. Solutions of disodium 2-succinylbenzoate were prepared by hydrolysis of the dilactone (Guest, 1977) and added to media at a final concentration of $10 \mu \mathrm{M}$ (solid media) or $25 \mu \mathrm{M}$ (liquid media). The 1,4-dihydroxy-2-naphthoate was stored anaerobically at $-14{ }^{\circ} \mathrm{C}$ and fresh solutions prepared in potassium buffer $(0 \cdot 1 \mathrm{M}, \mathrm{pH} 7 \cdot 0)$ were added at $4 \mu \mathrm{M}$ final concentration.

The media for routine subculture and maintenance were $\mathrm{L}$ agar and L broth (Lennox, 1955).

Isolation of mutants. Menaquinone mutants were isolated from strain JRG911 by treatment with 1-methyl3-nitro-1-nitrosoguanidine according to the procedure of Lambden \& Guest (1976). Mutant phenotypes were expressed by growth in LF medium supplemented with SB $(25 \mu \mathrm{M})$ or DHN $(4 \mu \mathrm{M})$ under an atmosphere of $\mathrm{H}_{2} / \mathrm{CO}_{2}(95: 5, \mathrm{v} / \mathrm{v})$ with shaking. This was followed by two cycles of anaerobic penicillin selection using unsupplemented LF medium and survivors from each cycle were plated on lactate medium and incubated aerobically. Mutants were detected by replicating to LF medium followed by anaerobic incubation. Potential mutants were then picked, purified aerobically and tested anaerobically on LF medium with and without supplements of SB or DHN. The men mutants represented $6 \%$ (after one enrichment cycle) or $30 \%$ (after two cycles) of the fumarate non-utilizing mutants obtained. Only one isolate of a particular type was saved from each treated culture.

Mutants resistant to nalidixic acid $\left(20 \mu \mathrm{g} \mathrm{ml}^{-1}\right)$ were isolated according to Lambden \& Guest (1976).

Fluoroacetate-resistant mutants $(f a c)$ were isolated according to Brown et al. (1977) using minimal media containing sodium pyruvate $(25 \mathrm{~mm})$ as substrate and sodium fluoroacetate $(10$ or $50 \mathrm{~mm})$. The secondary screen for failure to grow on acetate or impaired use of this substrate was not included.

Growth tests. Quantitative growth tests were performed according to Guest (1977) using anaerobic jars incubated with gentle shaking (fumarate-containing media) or without shaking (glucose media) under an 
atmosphere of $\mathrm{H}_{2} / \mathrm{CO}_{2}(95: 5, \mathrm{v} / \mathrm{v})$ unless stated otherwise. Maximum growth was recorded at $20 \mathrm{~h}$ for glucose media but longer was needed with fumarate media.

Enzymology. Cultures for enzymology were grown in $110 \mathrm{ml}$ medium (peptone, $0.4 \%$, w/v; yeast extract, $0.4 \%, w / v ; \mathrm{K}_{2} \mathrm{HPO}_{4}, 0.6 \%$, w/v; final $\mathrm{pH} \mathrm{6.8)} \mathrm{in} \mathrm{medical} \mathrm{flat} \mathrm{bottles} \mathrm{filled} \mathrm{to} \mathrm{the} \mathrm{neck} \mathrm{and} \mathrm{incubated}$ without shaking for $16 \mathrm{~h}$ at $37^{\circ} \mathrm{C}$. The inoculum was $0.1 \mathrm{ml}$ of an overnight $\mathrm{L}$ broth culture. The bacteria were harvested and washed and ultrasonic extracts were prepared according to Brown et al. (1977). The specific activities of acetate kinase (ATP:acetate phosphotransferase; EC 2.7.2.1) and phosphotransacetylase (acetyl-CoA:orthophosphate acetyltransferase; EC 2.3.1.8) were determined as described by Brown et al. (1977).

Genetic methods. Conjugations were performed by cross-streaking (Lambden \& Guest, 1976) and quantitatively in nutrient broth (Spencer \& Guest, 1973) using appropriate nutritional selections. Transduction with phage P1 was by the method of Spencer et al. (1976) using a multiplicity of infection of 2. Appropriate self-crosses and reversion controls were included. Transductants were selected on lactate plus fumarate $\left(\mathrm{men}^{+}, \mathrm{pta}^{+}\right.$and $\left.\mathrm{facA} \mathrm{A}^{+}\right)$, $\alpha$-glycerophosphate $\left(\mathrm{glp} \mathrm{T}^{+}\right)$or glucose $\left(\mathrm{purF} \mathrm{F}^{+}\right)$. The frequencies of complete transduction relative to the number of phages added were determined from colony counts after 2 to $5 \mathrm{~d}$ depending on the selection. Transductants were carefully purified by streaking to single colonies on the selective medium before scoring the inheritance of unselected markers by replica-plating on appropriate media. When present, abortive men $^{+}$transductants were clearly visible under low-power magnification as numerous small colonies against a recipient lawn, which varied in thickness depending on the specific cross and the recipient used.

Chemicals. Samples of DHN and the dilactone of 2-succinylbenzoate were kindly provided by Professor $\mathbf{R}$. Bentley and Dr D. R. Threlfall. Sodium fluoroacetate (B.D.H., Technical Grade) was purified by precipitation from aqueous solution with acetone. Sodium pyruvate, acetylphosphate(lithium salt), ATP (disodium salt), coenzyme A (free acid), NAD ${ }^{+}$(free acid), citrate synthase and malate dehydrogenase were from Boehringer.

\section{RESULTS}

\section{Isolation and nutritional characterization of the menaquinone mutants}

Twelve independent mutants blocked in the early stages of the menaquinone pathway were isolated after enriching for strains lacking the ability to use fumarate as the terminal electron acceptor unless supplied with supplements of 2-succinylbenzoate (SB) or 1,4dihydroxy-2-naphthoate (DHN). In addition, a partially characterized mutant (JRG860, S5 of Lambden \& Guest, 1976) and the two menaquinone mutants studied previously (Guest, 1977), were included in this investigation.

All 15 mutants resembled typical 'men mutants in their nutritional phenotypes. Thus, anaerobic growth on glucose was impaired but could be restored to normal with exogenous uracil and no anaerobic growth occurred on fumarate (F), formate plus fumarate (FF), lactate plus fumarate (LF) or glycerol plus fumarate (GF) media. Aerobic growth on glucose, glycerol or lactate and the ability to grow anaerobically with nitrate as the terminal electron acceptor were unaffected. Two distinct nutritional classes of mutant were detected by their anaerobic growth responses to menaquinone biosynthetic intermediates on glucose and LF media (Table 2). One class, represented by two mutants (JRG954, men-10, and JRG962, men-15) responded to DHN but not SB. These resemble the SB-accumulating mutants (menB; Young, 1975) and may lack the DHN synthetase activity detected by Bryant \& Bentley (1976). However, the cyclization reaction may involve more than one enzymic step or the participation of an enzyme containing non-identical subunits, so different genes could be affected in mutants of this nutritional phenotype. The men-10 strain was provisionally designated as a men $B$ mutant but the men-15 mutation was not assigned a specific gene symbol. The second nutritional class contained mutants which responded to both SB and DHN (Table 2) and appeared to be blocked in the early step(s) of the menaquinone pathway. Subsequent genetic studies (see below) indicated the presence of at least two genetically distinct groups within this nutritional class. One group contained the two menC mutants investigated previously (Guest, 1977) together with five new mutants. Another group, designated men $D$, contained three of the new mutants and could include a further three mutants which were not fully characterized (Table 2). One of the menC mutants (JRG952, menC8) was slower to respond to SB as growth supplement than the other mutants. 


\section{Table 2. Anaerobic growth of men mutants of E. coli}

Saline suspensions were streaked to infinite dilution on plates of solid medium supplemented with uracil $(\mathrm{U}, 360 \mu \mathrm{M})$, 2-succinylbenzoate $(\mathrm{SB}, 25 \mu \mathrm{M})$ or 1,4-dihydroxy-2-naphthoate (DHN, $4 \mu \mathrm{M}$ ) and incubated under $\mathrm{H}_{2} / \mathrm{CO}_{2}$. Growth was scored daily and related to wild-type controls: + , good growth (equivalent to wild-type); $(+)$, poor but significant growth; - , no growth.

\begin{tabular}{|c|c|c|c|c|c|c|c|}
\hline $\begin{array}{r}\text { Substrate } \\
\text { Terminal electron acceptor }\end{array}$ & \multicolumn{4}{|c|}{$\begin{array}{l}\text { Glucose } \\
\text { None }\end{array}$} & \multicolumn{3}{|c|}{$\begin{array}{l}\text { Lactate } \\
\text { Fumarate }\end{array}$} \\
\hline Supplement & None & $\mathrm{U}$ & SB & DHN & None & SB & DHN \\
\hline 962 (men-15) & $(+)$ & + & $(+)$ & + & - & - & + \\
\hline $\begin{array}{l}(\text { men } C 2), J R G 860(\text { men } C 3), \\
2(m e n C 8), J R G 953(\text { men } C 9),\end{array}$ & & & & & & & \\
\hline $\begin{array}{l}(\text { men } 6), J R G 918(\text { men } 7), \\
(m e n-12), J R G 959(\text { men-13) }\end{array}$ & $(+)$ & + & + & + & - & + & + \\
\hline
\end{tabular}

Despite repeated attempts using different methods, no cross-feeding could be detected between any of the mutants when tested in all possible pairwise combinations with fumarate media. All the mutants were fed by the parental strains and by spontaneous revertants. It has been reported that men $B$ mutants accumulate SB (Young, 1975), but the DHNrequiring mutants investigated here do not seem to excrete sufficient to promote the growth of menC or menD mutants.

The results of quantitative growth tests with different mutants are summarized in Fig. 1. The men B10 mutant (JRG954) responded to DHN but not to SB (Fig. 1a) and similar results were obtained with the nutritionally related strain JRG962 (men-15). The representative menD mutant (JRG918) responded to both intermediates (Fig. $1 b$ ) and similar results were obtained in quantitative tests with a menC mutant (JRG862). Of the two intermediates, DHN was clearly the most effective growth factor because it was active at concentrations 5 and 50 times lower than SB on LF and glucose media, respectively. At high concentrations $(>10 \mu \mathrm{M}) \mathrm{DHN}$ inhibited growth. The requirement for both intermediates was much lower on glucose than LF medium (Fig. 1). This supports the view that menaquinone-linked oxido-reduction reactions perform a relatively minor role during glucose fermentation but a major role when anaerobic metabolism is coupled to the reduction of fumarate. Growth over the optimal range of supplement concentrations was equivalent to that obtained with the parental strains on the same media. Analogous quantitative tests showed that the dilactone form of SB could replace the unhydrolysed derivative. The dilactone was consistently 1.5 to 2 times more active for promoting the growth of the SB-requiring mutants but it would not support growth of either of the DHN-requiring strains.

Preliminary growth tests had shown that the rate and extent of anaerobic growth on LF medium was influenced by the culture volume and the mode of incubation (stationary or with shaking). For example, the growth yields of stationary cultures were only $70 \%$ of those obtained with comparable shaken cultures. No such difference was found with glucose medium; this suggests that the gas phase contributes to the energy metabolism of cultures growing with fumarate as the reducible substrate even with lactate present. The importance of $\mathrm{H}_{2}$ was investigated by comparing the growth of the parental strain (PL2024, men ${ }^{+}$) on different media containing fumarate with either $\mathrm{H}_{2}$ or $\mathrm{He}$ as the major component of the gas phase (Fig. 2). It is clear that $\mathrm{H}_{2}$, formate or glycerol are essential for good anaerobic growth with fumarate. It is also clear that lactate is a relatively poor oxidizable substrate and that the good growth normally observed with the lactate plus fumarate medium is largely due to the use of an atmosphere containing $\mathrm{H}_{2}$. The presence of $\mathrm{H}_{2}$ had no significant effect on the yields obtained with formate or glycerol as oxidizable substrates. When the $\mathrm{H}_{2} / \mathrm{CO}_{2}$ mixture was replaced by $\mathrm{H}_{2}$ alone, the initial growth rates were lower but the 

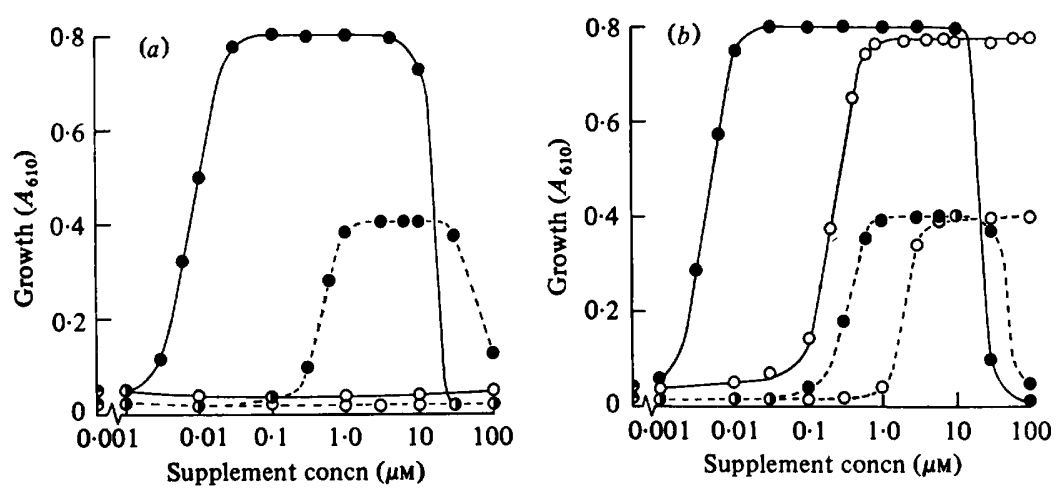

Fig. 1. Anaerobic growth responses of strain JRG954 (menB10)(a) and strain JRG918 (menD7)(b) to 1,4-dihydroxy-2-naphthoate $(\bullet)$ and 2-succinylbenzoate $(O)$ on glucose $(-)$ and lactate plus fumarate (-- ) media. Cultures were grown under $\mathrm{H}_{2} / \mathrm{CO}_{2}$ at $37{ }^{\circ} \mathrm{C}$ for $24 \mathrm{~h}$ (glucose) and $44 \mathrm{~h}$ (lactate plus fumarate).

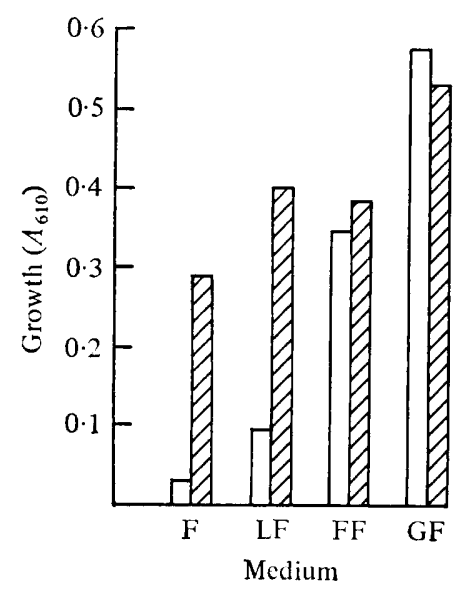

Fig. 2. Effect of hydrogen on the anaerobic growth yield of the parental strain of $E$. coli (PL2024) on fumarate media containing lactate (LF), glycerol (GF), formate (FF) or no additional organic substrate (F). Final growth was measured after $40 \mathrm{~h}$ at $37^{\circ} \mathrm{C}$ under $\mathrm{He} / \mathrm{CO}_{2}(\square)$ or $\mathrm{H}_{2} / \mathrm{CO}_{2}(\square)$.

final yields were unaffected. Similar results were obtained when representatives of all classes of men mutant were tested with different substrates and gas phases, provided that the media contained appropriate supplements of SB or DHN.

\section{Genetic studies with the menaquinone mutants}

Chromosomal location of men mutations. Preliminary cross-streak conjugation tests between the F-prime donor strain F129 and all the men mutants were performed by selecting for the ability to use fumarate as an anaerobic electron acceptor and counter-selecting against the donor with nalidixic acid. Weak positive results were obtained indicating that all the men mutations are situated in the 44 to 55 min region of the E. coli linkage map. This conclusion was confirmed by quantitative tests and the relatively low yields of $\mathrm{men}^{+} \mathrm{nal}$ conjugants $(0.04$ to $0.25 \%$ of donor input) are readily explained by the close proximity of the men and nalA markers. Cross-streak conjugation was also used to show that none of the men mutations were suppressible by the supU amber suppressor of strain AW9.

Transduction studies with phage P1 confirmed that all the men mutations are located in 
Table 3. Transductional linkage relationships between nalA, glpT, purF and men markers

Phage P1-mediated transductional linkage analysis was performed by the techniques described in the Methods.

\begin{tabular}{|c|c|c|c|c|c|c|c|}
\hline Cross & Donor & Recipient & $\begin{array}{l}\text { Selected } \\
\text { marker }\end{array}$ & $\begin{array}{c}\text { Trans- } \\
\text { duct- } \\
\text { tants } \\
\text { per } \\
10^{6} \mathrm{P} 1\end{array}$ & $\begin{array}{l}\text { No. } \\
\text { scored }\end{array}$ & $\begin{array}{l}\text { Unsel- } \\
\text { ected } \\
\text { donor } \\
\text { marker }\end{array}$ & $\begin{array}{l}\text { Cotrans- } \\
\text { duction } \\
\text { fre- } \\
\text { quency } \\
(\%)\end{array}$ \\
\hline 1 & PL2024 & JRG914 (menC3 nalA) & $m e n C^{+}$ & 24 & 120 & $\operatorname{nalA}^{+}$ & 21 \\
\hline 2 & PL2024 & JRG918 (menD7 nalA) & $m e n D^{+}$ & 16 & 100 & nalA ${ }^{+}$ & 22 \\
\hline 3 & PL2024 & JRG954 (menBl0 nalA) & menB $B^{+}$ & 10 & 100 & nalA $^{+}$ & 16 \\
\hline 4 & PL2024 & JRG962 (men-15 nal $A)$ & $m^{\prime} n^{+}$ & 8 & 100 & nalA & 14 \\
\hline 5 & JRG896 (purF) & JRG914 (menC3 nalA) & $\operatorname{men} C^{+}$ & 9 & 100 & purF & 10 \\
\hline 6 & JRG896 (purF) & JRG918 (menD7 nalA) & $m e n D^{--}$ & 13 & 100 & purF & 14 \\
\hline 7 & JRG896 (purF) & JRG954 (menBI0 nalA) & $\operatorname{men} B^{+}$ & 12 & 90 & purF & 16 \\
\hline 8 & JRG896 (purF) & JRG962 (men-15 nalA) & $\operatorname{men}^{+}$ & 6 & 92 & purF & 14 \\
\hline 9 & $\operatorname{Lin} 6(g l p T)$ & JRG914 (menC3 nalA) & men $C^{+}$ & 56 & 100 & $g l p T$ & 39 \\
\hline 10 & Lin6 $(g l p T)$ & JRG918 (menD7 nalA) & $\operatorname{men} D^{+}$ & 60 & 100 & $g l p T$ & 34 \\
\hline 11 & $\operatorname{Lin} 6(g l p T)$ & JRG954 (menB10 nalA) & $m e n B^{+}$ & 62 & 100 & $g l p T$ & 30 \\
\hline 12 & JRG954 (menB10 nalA) & Lin6 $(g l p T)$ & $g l p T^{+}$ & 12 & 134 & men $B$ & 26 \\
\hline
\end{tabular}

the same region of the chromosome. Representative results of linkage determinations between representative men markers and nal $A$, purF and $g l p T$ markers are shown in Table 3 . Average values for all pairs of markers were: men-nalA, 20.7\% (range 14 to 27\%); menpurF, $14.7 \%$ (range 9 to $24 \%$ ); men-glpT, 35.4\% (range 30 to $40 \%$ ). No significant differences were observed for different classes of men mutants. The distribution of nalA and purF markers in over 1500 men $^{+}$transductants derived from crosses of type 5 to 8 (Table 3) was: nalA ${ }^{+}$pur $F^{+}, 20.7 \%$; nal $A^{+}$purF, $0.7 \%$; nalA purF $F^{+}, 64.6 \%$; nalA pur $F, 14.0 \%$. This is consistent with the gene order: nalA-men-purF. It is also shows that linkage between the rather distant pair of markers nal $A$ and $p u r F$ can be demonstrated when the internal marker $\left(m^{+} n^{+}\right)$is selected. The distribution of nalA and $g l p T$ markers in the $m^{+} n^{+}$transductants derived from all the crosses of type 9 to 11 (Table 3) was: $n a l A^{+} g l p T^{+}, 0.4 \% ; n a l A^{+} g l p T$, $16.1 \%$; nalA $g l p T^{+}, 64.3 \%$; nalA $g l p T, 19.3 \%$. This is consistent with the gene order: nal $A-g l p T$-men. The same order is supported by the distribution of nal $A$ and men $B$ markers in a reciprocal cross (cross 12, Table 3): nal $A^{+}$men $B^{+}, 22 \%$; nal $A^{+}$men $B, 17 \%$; nalA men $B^{+}$, $52 \%$; nalA men $B, 9 \%$. Thus, regardless of their phenotypes, all the men mutants have mutations clustered between the $g l p T$ and $p u r F$ genes. The results of this analysis are summarized in the linkage map shown in Fig. 3. They agree with earlier results with the exception that the $g l p T$-men linkage is somewhat lower than a previous estimate of $51 \%$ (Guest, 1977). Abortive $m^{+} n^{+}$transductants were observed with all the men mutants in crosses involving $\mathrm{men}^{+}$donors and selection for $\mathrm{men}^{+}$transductants.

Fine structure and complementation analysis. The route postulated for the biosynthesis of DHN from chorismate could be governed by more than two genes (menC and men $B$ ). To investigate this possibility, the men mutants were crossed in many pairwise combinations; $m^{+} n^{+}$transductants were selected and the presence of abortive transductants was used as a complementation test. At the same time these crosses were arranged so that the distribution of an unselected nalA marker could be scored to elucidate the relative orientations of the corresponding markers. The transduction frequencies for different pairs of mutants were invariably low and no unique and unambiguous linkage map could be derived from the two-factor data, even after normalization by reference to $t r p^{+}$transduction frequencies obtained with a wild-type donor and the same recipients in parallel crosses. However, useful three-factor data was obtained and, in most cases, abortive transduction provided a significant complementation test. Some of the results are presented in Table 4. Initially, a P1 


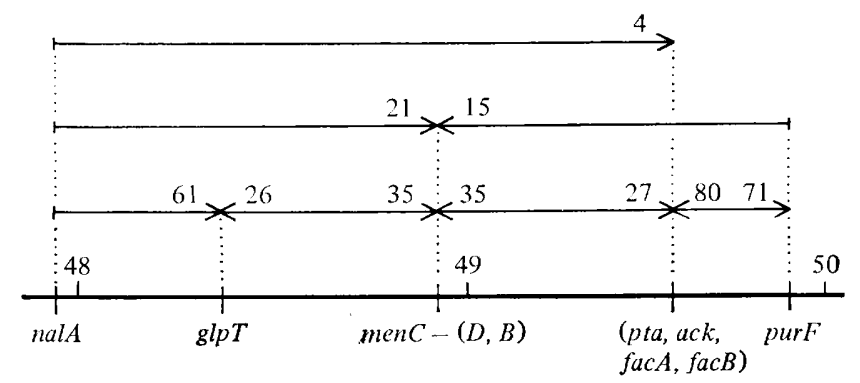

Fig. 3. Linkage map of Escherichia coli in the 48 to $50 \mathrm{~min}$ region showing the positions of genes governing menaquinone biosynthesis ( $m e n$ ) and fluoroacetate-resistance ( $f a c A, f a c B$, ack and $p t a$ ). The map distances are average cotransduction frequencies $(\%)$ and these are placed near the head of the arrow pointing to the selected marker in the corresponding crosses. The parentheses denote that the relative orders of the enclosed genes are uncertain.

Table 4. Representative three-factor transductional crosses between men mutants

Transductants $\left(\mathrm{men}^{+}\right)$were selected anaerobically on LF medium, purified and scored for the inheritance of the unselected nal marker (see Methods).

\begin{tabular}{|c|c|c|c|c|c|c|}
\hline Cross & Donor & Recipient & $\begin{array}{l}\text { Trans- } \\
\text { duction } \\
\text { frequency } \\
\text { (no. per } \\
10^{7} \mathrm{P} 1 \text { ) }\end{array}$ & $\begin{array}{l}\text { No. } \\
\text { scored }\end{array}$ & $\begin{array}{c}\text { Inheritance } \\
\text { of } \\
\text { donor nal } \\
\text { marker }\end{array}$ & Order indicated \\
\hline 13 & JRG860 (menC3) & JRG914 (menC3 nalA) & $<0.02$ & 一 & 一 & 一 \\
\hline 14 & JRG860 (menC3) & JRG917 (menD6 nalA) & $3 \cdot 5$ & 98 & $3 \% \mathrm{nal}^{+}$ & nalA...men $C-$ menD \\
\hline 15 & JRG860 (menC3) & JRG918 (menD7 nalA) & $2 \cdot 6$ & 98 & $3 \% \mathrm{nal}^{+}$ & nalA...men $C-$ men $D$ \\
\hline 16 & JRG860 (menC3) & JRG954 (menB10 nalA) & $1 \cdot 8$ & 69 & $4 \% \mathrm{nal}^{+}$ & nal $A \ldots$ men $C-$ men $B$ \\
\hline 17 & JRG860 (menC3) & JRG962 (men-15 nalA) & $3 \cdot 8$ & 84 & $12 \% \mathrm{nal}^{+}$ & $?$ \\
\hline 18 & JRG918 (menD7 nalA) & JRG1047 (menD7) & $<0.05$ & - & 一 & 一 \\
\hline 19 & JRG918 (menD7 nalA) & JRG862 (menCl) & $22 \cdot 9$ & 145 & $19 \cdot 2 \%$ nal & nalA...men $C-$ menD \\
\hline 20 & JRG918 (menD7 nalA) & JRG860 (menC3) & $8 \cdot 3$ & 137 & $25 \cdot 5 \% \mathrm{nal}$ & nalA...men $C-\operatorname{men} D$ \\
\hline 21 & JRG918 (menD7 nalA $)$ & JRG1049 (menB10) & $<0.05$ & - & - & - \\
\hline 22 & JRG1047 (menD7) & JRG962 (men-15 nalA) & $<0.05$ & 一 & $\longrightarrow$ & - \\
\hline 23 & JRG954 (menB10 nalA) & JRG1049 (menB10) & $<0.02$ & 一 & - & - \\
\hline 24 & JRG954 (menB10 nalA) & JRG862 (menCl) & $1 \cdot 4$ & 102 & $17 \cdot 6 \%$ nal & nal $A . .$. men $C-$ men $B$ \\
\hline 25 & JRG954 (menB10 nalA) & JRG860 (menC3) & $1 \cdot 5$ & 60 & $16.7 \%$ nal & nalA...men $C-$ menB \\
\hline 26 & JRG954 (menBl0 nalA) & JRG1047 (menD7) & $<0.05$ & - & - & - \\
\hline 27 & JRG954 (menB10 nalA) & JRG962 (men-15 nalA) & $1 \cdot 0$ & 一 & - & - \\
\hline
\end{tabular}

lysate of one mutant (JRG860, menC3) was crossed with nalidixic acid resistant derivatives of all 15 men mutants. Seven of the recipients yielded $m e n^{+}$complete transductants at low frequencies $\left(<0.02\right.$ to 0.5 per $\left.10^{7} \mathrm{P} 1\right)$ and no abortive transductants. The corresponding mutations (men-1, $-2,-3,-4,-8,-9$ and -14 ) were accordingly assigned to a single class, menC. The remaining eight mutants, including the two with the obligate DHN requirement, gave higher frequencies of $m^{+} n^{+}$complete transduction $\left(1.5\right.$ to 25 per $\left.10^{7} \mathrm{P} 1\right)$ and an abundance of $\mathrm{men}^{+}$abortive transductants. The donor $\mathrm{nal}^{+}$marker was inherited by only 1 to $4 \%$ of the $\mathrm{men}^{+}$complete transductants for all but one recipient. These cotransduction frequencies are considerably less than normal for nal and men markers (14 to $27 \%$ ) and indicate that the corresponding mutations (men-5, -6, -7, -10,-11, -12,-13) are all further from nal $A$ than the menC mutants. Representative results are shown in Table 4 (crosses 14 to 16). For the exceptional recipient (a DHN-requiring mutant: JRG962, men-15), the outside marker distribution was rather inconclusive (Table 4, cross 17). Consequently, no firm decision about the site of the men-15 mutation relative to nalA and menC3 was possible.

The existence of two distinct clusters of complementing mutations generating the same 
nutritional phenotype suggests that at least two genes (menC and $m e n D$ ) are responsible for the biosynthesis of SB. One mutant (JRG918, menD7) was selected as representing the second class and used as the donor in analogous transductional crosses. The outside marker distribution and the presence of abortive transductants confirmed that the men-1, $-2,-3,-4$ $(m e n C)$ mutations form a distinct complementation group closer to nalA than the menD mutants (men-5, -6, -7). Representative results for these crosses are shown in Table 4 (crosses 19 and 20 ).

Using the menB mutant (JRG954, menB10) as donor, men $^{+}$complete and abortive transductants were obtained with the menC mutants. Moreover, the gene order: nalAmen $C$-men $B$ (indicated in cross 16 ) was confirmed by the reciprocal three-factor crosses (e.g. Table 4, crosses 24 and 25). Crosses between the two DHN-requiring mutants (e.g. Table 4, cross 27) produced complete transductants at low frequencies but as complementation tests they were inconclusive: indistinct micro-colonies were seen but they were less obvious than typical abortive transductants. Consequently, it was not possible to establish whether or not the men-15 mutation belongs to the same complementation group as the men 10 mutation. Failure to obtain P1 lysates of the men-15 mutant prevented both its use as a donor and the construction of the corresponding $\mathrm{nal}^{+}$derivative. Also, despite repeated attempts using different $\mathrm{nal}^{+}$and nal derivatives, crosses designed to determine the relative orders of the menD, menB10 and men-15 sites (e.g. crosses 21, 22, 26; Table 4) were frustrated by the failure to obtain significant numbers of $m^{+} n^{+}$transductants or, in some cases, by the poor selectivity of the LF medium. Therefore, the relative positions of the complementation groups can only be summarized thus: nalA...men $C-(D, B) \ldots$ pur $F$, to denote that the position of $m e n B$ relative to $m e n D$ is uncertain.

\section{Studies with fluoroacetate-resistant mutants}

Recent studies with fluoroacetate-resistant mutants have located two genes, ack (acetate kinase) and pta (phosphotransacetylase), close and anticlockwise to purF (Brown et al., 1977). Because these markers were potentially useful as outside markers for fine-structure analysis of the men mutants, fluoroacetate-resistant derivatives of several strains were isolated and their linkage relationships were investigated.

Forty-five independent fluoroacetate-resistant mutants ( $\mathrm{fac}$ ) were isolated from several parental strains. Growth tests on solid media revealed the presence of two relatively distinct nutritional groups, designated A and B. Members of group A (representing $40 \%$ of the isolates) were characterized by their failure to grow anaerobically on glucose minimal medium and on LF, GF, FF and $\mathrm{F}$ media under $\mathrm{H}_{2} / \mathrm{CO}_{2}$. By contrast, group B mutants grew under these conditions. All of the mutants grew aerobically on glucose and growth on acetate was either very poor (group A) or impaired (group B). Enzymological studies with 21 mutants, 12 from group A and 9 from group B, showed that the two nutritional groups each contained several biochemically distinct classes (Table 5). The mutants of one class (1) were defined as acetate kinase (ack) mutants because they were solely deficient in this activity. Their nutritional phenotype (group B) indicates that acetate kinase is not essential for anaerobic growth with fumarate. Three mutants (class 2 ) lacked only phosphotransacetylase and were designated pta mutants. However, they were placed in different sub-classes (2a and $2 \mathrm{~b}$ ) because two had no detectable activity and failed to grow anaerobically on glucose and fumarate media (nutritional group A), whereas the other appeared to retain sufficient activity to support growth under these conditions (Table 5). The largest class (3) contained mutants deficient in both acetate kinase and phosphotransacetylase and all were incapable of growth by glucose fermentation or fumarate reduction (Table 5). The existence of such mutants was not reported previously by Brown et al. (1977). They were considered as a single class, designated $f a c A$, although different types of mutant may be present. For example, this class could include regulatory mutants or, if the ack and pta genes are closely linked components of the same transcriptional unit, deletion mutants and polar mutants . 
Table 5. Biochemical characteristics of fluoroacetate-resistant mutants

The mutants were arranged into different classes according to their specific activities for acetate kinase and phosphotransacetylase compared with their parental strains [acetate kinase, $7 \cdot 4 \mu \mathrm{mol}$ (mgprotein) ${ }^{-1} \mathrm{~min}^{-1}$; phosphotransacetylase, $\left.5 \cdot 4 \mu \mathrm{mol}(\mathrm{mg} \text { protein })^{-1} \mathrm{~min}^{-1}\right]$. Nutritional groups correspond to the inability (A) or ability (B) to grow by glucose fermentation or with fumarateas terminal electron acceptor.

\begin{tabular}{|c|c|c|c|c|c|}
\hline \multirow[b]{2}{*}{ Class } & \multirow[b]{2}{*}{ Mutant allele } & \multicolumn{2}{|c|}{$\begin{array}{c}\text { Enzyme specific activity } \\
(\% \text { of parental })\end{array}$} & \multirow[b]{2}{*}{$\begin{array}{l}\text { Nutritional } \\
\text { group }\end{array}$} & \multirow[b]{2}{*}{$\begin{array}{l}\text { Genetic } \\
\text { designation }\end{array}$} \\
\hline & & $\begin{array}{l}\text { Acetate } \\
\text { kinase }\end{array}$ & $\begin{array}{l}\text { Phospho- } \\
\text { transacetylase }\end{array}$ & & \\
\hline 1 & fac- $11,17,26,31,37$ & $<0.4-14.5$ & $65-100$ & B & ack \\
\hline $\begin{array}{l}2 \mathrm{a} \\
2 \mathrm{~b}\end{array}$ & $\begin{array}{l}f a c-47 \\
f a c-36,39\end{array}$ & $\begin{array}{l}100 \\
100\end{array}$ & $\begin{array}{l}26 \\
<0 \cdot 2\end{array}$ & $\left.\begin{array}{l}\mathrm{B} \\
\mathrm{A}\end{array}\right\}$ & pta \\
\hline $\begin{array}{l}3 a \\
3 b\end{array}$ & $\begin{array}{l}\text { fac- }-9,12,21,27,28,33,38,42,46 \\
\text { fac- } 15\end{array}$ & $\begin{array}{l}<0.4 \\
<0.4\end{array}$ & $\begin{array}{r}<0.2 \\
6.4\end{array}$ & $\begin{array}{l}\mathrm{A} \\
\mathrm{A}\end{array}$ & $f a c A$ \\
\hline 4 & $f a c-7,14,32$ & $60-100$ & $80-100$ & $\mathbf{B}$ & $f a c B$ \\
\hline
\end{tabular}

The enzymological properties of one mutant $(f a c-15)$ are consistent with it possessing a polar ack mutation which limits the expression of a distal pta gene. Another new class of fluoroacetate-resistant mutant (class $4, f a c B$ ) possessed both acetate kinase and phosphotransacetylase and no nutritional defect (group B): the corresponding metabolic lesion is unknown.

Several mutants from each class were used to investigate the linkage relationships between the fluoroacetate-resistance mutations and men, purF and nalA markers. Representative transductional crosses are shown in Table 6 and average values for the cotransduction frequencies obtained from all relevant crosses are summarized in Fig. 4. These indicate that all of the $a c k, p t a, f a c A$ and $f a c B$ mutations are situated between the men and purF genes. Detailed analyses of the various classes of recombinant arising from the three- and fourfactor crosses confirmed this location relative to the nal A, men and purF genes. No significant differences were observed for the four classes of fluoroacetate-resistance mutations indicating that all four classes are tightly clustered. The ack locus appeared to be closer to purF than reported previously [ $70 \%$ cotransduction compared with 41 and $56 \%$ reported by Brown et al. (1977)] but the linkage between pta and purF $(73 \%)$ is in good agreement with the value of $68 \%$ reported previously. No segregation of the nutritional phenotype (group A or B) from the fluoroacetate-resistance phenotype was observed with any of the mutants. In fact, selection for growth on LF medium proved a very useful method for obtaining fluoroacetate-sensitive transductants of all fac $A$ mutants and one of the pta mutants (JRG1089, pta-39). This selection was not possible with mutants of nutritional group B, nor was it sufficiently selective for genetic studies with one of the group A mutants, pta-36.

These results indicated that fluoroacetate-resistance mutations of the $a c k$ and $f a c B$ type could be used as outside markers for fine-structure genetic analysis of men mutants. However, the fact that many mutations causing fluoroacetate-resistance interfere with the selection for $\mathrm{men}^{+}$transductants on LF medium offsets the advantage of their slightly closer proximity to men ( 27 to $35 \%$ cotransduction frequency) than the other convenient outside marker, nalA (21\% cotransduction frequency). Average linkage values for all types of fluoroacetate-resistance mutation with other markers are included in Fig. 3.

\section{DISCUSSION}

The successful isolation of typical men mutants as SB or DHN auxotrophs during fumarate-dependent anaerobic growth justified the validity of the selection procedure adopted. The nutritional phenotypes of the mutants are also consistent with a route for menaquinone 
Table 6. Representative transductional linkage relationships between different types of fluoroacetate-resistance markers (ack, pta, facA and facB) and neighbouring markers

Transductions were performed as described in the Methods. The LF medium was used as the selective medium with fac $A$ and pta mutants and 2-succinylbenzoate was added when menC was an unselected marker.

\begin{tabular}{|c|c|c|c|c|c|c|c|}
\hline Cross & Donor & Recipient & $\begin{array}{l}\text { Selected } \\
\text { marker }\end{array}$ & $\begin{array}{l}\text { Trans- } \\
\text { ductants } \\
\text { per } 10^{6} \\
\text { P1 }\end{array}$ & $\begin{array}{l}\text { No. } \\
\text { scored }\end{array}$ & $\begin{array}{l}\text { Unsel- } \\
\text { ected } \\
\text { donor } \\
\text { marker }\end{array}$ & $\begin{array}{c}\text { Cotrans- } \\
\text { duction } \\
\text { fre- } \\
\text { quency } \\
(\%)\end{array}$ \\
\hline 28 & JRG1061 (ack-11) & JRG954 (menB10 nalA) & $m e n B^{+}$ & 5 & 81 & ack & 27 \\
\hline 29 & PL2024 & JRG1081 (ack-31 purF) & purF+ & 5 & 115 & $a c k^{+}$ & 62 \\
\hline 30 & JRG1081 (ack-31 purF) & JRG954 (menB10 nalA) & $\operatorname{men} B^{+}$ & 16 & 82 & ack & 33 \\
\hline 31 & JRG914 (menC3 nalA) & JRG1089 (pta-39 purF) & $p_{t a}^{+}$ & 10 & 128 & $\begin{array}{l}\text { menC } \\
\text { nalA }\end{array}$ & $\begin{array}{r}27 \\
3\end{array}$ \\
\hline 32 & JRG914 (menC3 nalA) & JRG1089 (pta-39 purF) & purFt+ & 23 & 164 & $p_{t a}^{+}$ & 73 \\
\hline 33 & JRG860 (men C3) & $\begin{array}{l}\text { JRG1092 (facA42 purF } \\
\text { nalA) }\end{array}$ & fac $A^{+}$ & 9 & 100 & $\begin{array}{l}\operatorname{menC} \\
\text { nalA } \\
\text { pur } F^{+}\end{array}$ & $\begin{array}{r}26 \\
5 \\
82\end{array}$ \\
\hline 34 & PL2024 & $\begin{array}{l}\text { JRG1092 (fac } A 42 \text { purF } \\
\text { nalA) }\end{array}$ & purF $F^{+}$ & 28 & 108 & $\mathrm{facA}^{+}$ & 74 \\
\hline 35 & $\begin{array}{l}\text { JRG1057 (nalA menB10 } \\
\text { facB7) }\end{array}$ & JRG896 (purF) & purF $F^{+}$ & 17 & 212 & $f a c B$ & 67 \\
\hline 36 & PL2024 & $\begin{array}{l}\text { JRG1057 (nalA menB10 } \\
\text { facB7) }\end{array}$ & $\operatorname{men} B^{+}$ & 26 & 164 & $f a c B^{+}$ & 39 \\
\hline
\end{tabular}

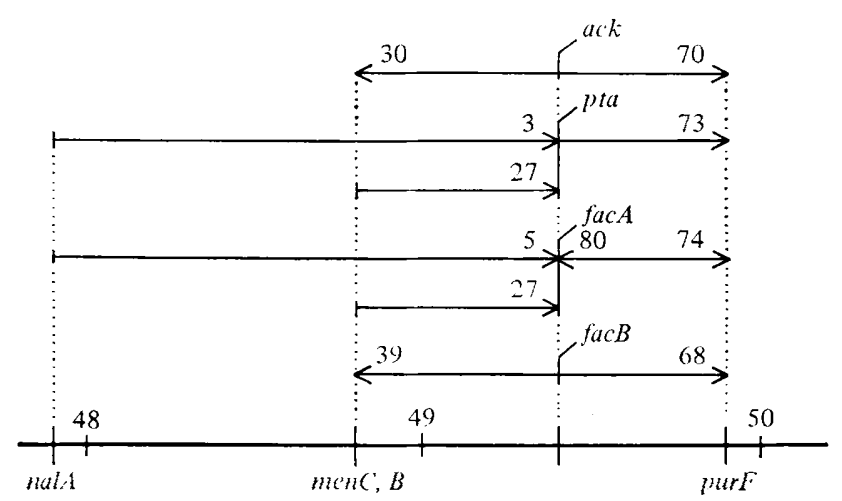

Fig. 4. Linkage map summarizing the cotransductional linkage relationships between the four classes of fluoroacetate-resistance markers and the neighbouring nalA and purF markers. Average cotransduction frequencies (\%) for all crosses of the type shown in Table 6 are placed near the head of the arrow pointing to the selected marker.

biosynthesis in which SB is a precursor of DHN. The corresponding mutations were all located in the $49 \mathrm{~min}$ region of the $E$. coli linkage map. This indicates that the men $B$ locus, not previously mapped, is close to the menC gene and some $38 \mathrm{~min}$ anti-clockwise of the $m e n A$ gene. The view that there may be more than two genes (men $B$ and men $C$ ) governing the early steps in menaquinone biosynthesis was supported by the genetic analysis of the new mutants. Using abortive transduction as a complementation test plus three-factor reciprocal crosses to order the sites, the existence of two distinct clusters of SB-requiring mutant was demonstrated. These results are most easily interpreted by postulating the existence of an independent men $D$ gene close and clockwise to the men $C$ gene. Technical difficulties prevented a thorough analysis of the two DHN-requiring mutants: they behaved sufficiently differently to suggest that two distinct complementation groups may be represented. The menB10 mutation appeared to be on the menD side of menC but its position 
relative to men $D$ could not be elucidated. Even less information concerning the location of the men-15 mutation was obtained. Some of the problems could be explained if one or both of these mutants contained two mutations, e.g. a mutation in the menD gene as well as in a gene governing DHN synthesis, or polar mutations. This would also explain their inability to cross-feed the SB-requiring mutants. No support for this complexity was obtained from reversion or suppression tests.

Growth tests indicated that $\mathrm{H}_{2}$, formate and glycerol are good oxidizable substrates for supporting growth with fumarate as electron acceptor. This parallels the situation found in Vibrio succinogenes (Kröger, 1977). In selecting for fumarate reduction-deficient mutants using lactate or glycerol under an atmosphere of $\mathrm{H}_{2}$ it is now clear that two oxidizable substrates were present (Lambden \& Guest, 1976) and this explains why the mutants were all defective in fumarate reduction and none had specific lesions in lactate or glycerol oxidation.

The fluoroacetate-resistant mutants possessed a much wider range of enzymological phenotypes than those described previously (Brown et al., 1977) and four basic groups were recognized. However, all the mutants had lesions in the region of the chromosome near purF and two- and three-factor crosses involving nalA, men and purF mutations confirmed that they map between men and purF. The ack and pta mutations appeared to be closer to $p u r F$ than reported previously (Brown et al., 1977). A large class ( $f a c A)$ lacking acetate kinase and phosphotransacetylase activities could represent deletion or polar mutants. There also appeared to be at least one other gene $(f a c B)$ concerned with fluoroacetate sensitivity in this region. Its function is not known but it could be connected either with the uptake or metabolism (lethal synthesis) of the inhibitor. This function, like acetate kinase, is not essential for growth with fumarate as electron acceptor. In fact only the mutants $(f a c A)$ lacking both acetate kinase and phosphotransacetylase and the most severely affected pta mutants failed to grow anaerobically on the fumarate-containing media. A possible explanation for this is the depletion of intracellular CoA by conversion to acetyl-CoA which cannot be recycled. Mutants of this type were not isolated as $\mathrm{LF}^{-}$or $\mathrm{GF}^{-}$mutants by Lambden \& Guest (1976), possibly because their aerobic growth on non-fermentable substrates is also impaired.

I am indebted to R. Bentley and D. R. Threlfall for generous gifts of chemicals and Helen M. Nice for skilled technical assistance.

\section{REFERENCES}

BachmanN, B. J., Low, K. B. \& TAYloR, A. L. (1976). Recalibrated linkage map of Escherichia coli K-12. Bacteriological Reviews 40, 116-167.

Brown, T. D. K., JONES-MORTIMER, M. C. \& KornBerG, H. L. (1977). The enzymic interconversion of acetate and acetyl-coenzyme $A$ in Escherichia coli. Journal of General Microbiology 102, 327-336.

BRYANT, R. W. \& BENTLEy, R. (1976). Menaquinone biosynthesis: conversion of $o$-succinylbenzoic acid to 1,4-dihydroxy-2-naphthoic acid and menaquinones by Escherichia coli extracts. Biochemistry 15, 4792-4796.

Creaghan, I. T. \& Guest, J. R. (1978). Succinate dehydrogenase-dependent nutritional requirement for succinate in mutants of Escherichia coli K12. Journal of General Microbiology 107, 1-13.

GotTschalK, G. \& ANDREESEN, J. R. (1979). Energy metabolism in anaerobes. In International Review of Biochemistry, vol. 21, Microbial Bio- chemistry, pp. 85-115. Edited by J. R. Quayle. Baltimore: University Park Press.

GuEST, J. R. (1977). Menaquinone biosynthesis: mutants of Escherichia coli $\mathrm{K}-12$ requiring 2succinylbenzoate. Journal of Bacteriology 130 , 1038-1046.

HADDOCK, B. A. \& JoNES, C. W. (1977). Bacterial respiration. Bacteriological Reviews 41, 47-99.

Hayashi, S., Koch, J. P. \& LiN, E. C. C. (1964). Active transport of $\mathrm{L}-\alpha$-glycerophosphate in Escherichia coli. Journal of Biological Chemistry 239, 3098-3105.

JACOBS, N. J. \& JACOBS, J. M. (1978). Quinones as hydrogen carriers for a late step in anaerobic heme biosynthesis in Escherichia coli. Biochimica et biophysica acta 544, 540-546.

KRöGER, A. (1977). Phosphorylative electron transport with fumarate and nitrate as terminal hydrogen acceptors. Symposia of the Society for General Microbiology 27, 61-93. 
Kröger, A. (1978). Fumarate as terminal acceptor of phosphorylative electron transport. Biochimica et biophysica acta 505, 129-145.

LAMBDEN, P. R. \& GúEST, J. R. (1976). Mutants of Escherichia coli $\mathrm{K} 12$ unable to use fumarate as an anaerobic electron acceptor. Journal of General Microbiology 97, 145-160.

LENNOX, E. S. (1955). Transduction of linked genetic characters of the host by bacteriophage P1. Virology 1, 190-206.

Low, K. B. (1972). Escherichia coli F-prime factors, old and new. Bacteriological Reviews 36, 587-607.

Newton, N. A., Cox, G. B. \& Gibson, F. (1971). The function of menaquinones (vitamin $\mathbf{K}_{2}$ ) in Escherichia coli K-12. Biochimica et biophysica acta 244, 155-166.
ShineberG, B. \& Young, I. G. (1976). Biosynthesis of bacterial menaquinone: the membraneassociated 1,4-dihydroxy-2-naphthoate octaprenyltransferase of Escherichia coli. Biochemistry 15, 2754-2758.

SPenCER, M. E. \& Guest, J. R. (1973). Isolation and properties of fumarate reductase mutants of Escherichia coli. Journal of Bacteriology 114, 563-570.

Spencer, M. E., Lebeter, V. M. \& Guest, J. R. (1976). Location of the aspartase gene $(\operatorname{asp} A)$ on the linkage map of Escherichia coli K12. Journal of General Microbiology 97, 73-82.

YounG, I. G. (1975). Biosynthesis of bacterial menaquinones. Menaquinone mutants of Escherichia coli. Biochemistry 14, 399-406. 